\title{
Modeling of induction motor drive of a mine hoist on the basis of a doubly-fed electric machine
}

\author{
Viktor Ostrovlyanchik ${ }^{1}$, Ivan Popolzin ${ }^{1 *}$, Vasiliy Kubarev ${ }^{1}$, and Dabin $\mathrm{Qi}^{2}$ \\ ${ }^{1}$ Siberian State Industrial University, Novokuznetsk, 654000, Russia \\ ${ }^{2}$ University of Science and Technology Liaoning, Anshan, 14051, China
}

\begin{abstract}
One of the options for the modernization of existing hoist electric drives with a wound-rotor induction motor is its starting according to the scheme of a doubly-fed machine. For this purpose, a frequency converter with an adjustable amplitude, frequency and phase shift of the voltage at its output is connected to the motor rotor. At the same time, the problem of obtaining a mathematical model of both the double fed machine itself and the speed control system based on it is relevant due to the need to take into account the additional supply voltage in the differential equations drawn up in accordance with the Kirchhoff's law for the stator and rotor windings. The paper proposes a structural diagram for the mathematical model of an induction motor drive of a hoist based on a doubly fed machine.
\end{abstract}

\section{Introduction}

One of the options for the modernization of existing electric drives of hoist with a woundrotor induction motor is the starting of a wound-rotor induction motor according to the scheme of a doubly-fed machine (DFM).

At the same time, the task of obtaining a mathematical model of both the DFM itself and the automatic speed control system (ASCS) based on it is relevant. The task is not only to implement the control system, but also to create a control object structure suitable for analysis and synthesis in electric drive control systems. In addition, the model is necessary for investigating and adjusting the drive operation, since direct experiments on such a complex and critical object are, as a rule, impossible.

\section{Construction of a mathematical model for an electric drive with a doubly-fed machine}

The electric drive of the hoist based on DFM consists of a wound-rotor induction motor, a controlled voltage converter, a controlled current converter, a reverser and a drive control

\footnotetext{
* Corresponding author: eidoline@yandex.ru
} 
system [1-4]. The controlled voltage converter provides control of the machine in the speed range $0,1 \omega_{0} \leq \omega \leq \omega_{0}$ when the speed is regulated upward from zero and in the speed range $0 \leq \omega \leq \omega_{0}$ when the speed is regulated downward from the nominal. A controlled current converter is necessary to implement the mode of release and acceleration of the machine in the range $0 \leq \omega \leq 0,1 \omega_{0}$, as well as an emergency reserve. SARS, consisting of torque and speed controllers, an intensity generator and a logical control system, controls the drive in accordance with the algorithm proposed in [1].

The system of equations describing the DFM when changing the frequency, amplitude and phase of the additional voltage on the rotor was obtained in [1] and looks as follows:

$$
\left\{\begin{array}{l}
\left(\omega_{0 e}-\omega\right) \pm \Delta \omega_{\kappa}-\left(\omega_{0}-\omega\right)=\Delta \omega \\
M=\left(\frac{C_{e r}}{p}+\beta\right)\left(\omega_{0}-\omega\right) \\
E_{R}=-k_{E} \omega+u_{S} \\
\Delta u_{R}=u_{R}+E_{R} \\
i_{R a}=\Delta u_{R} \cdot \frac{1 / R_{R}}{T_{R} p+1} \\
M_{a}=\frac{3 z_{P} L_{\mu}}{2 R_{S}} i_{R a} u_{S} \\
M_{\Sigma}=M_{a}+M \\
\omega=\frac{M-M_{C}}{J p}
\end{array}\right.
$$

The system of equations (1) can be associated with the equivalent structure of a doublyfed induction motor drive with a change in the frequency of additional voltage, shown in Fig. 1.

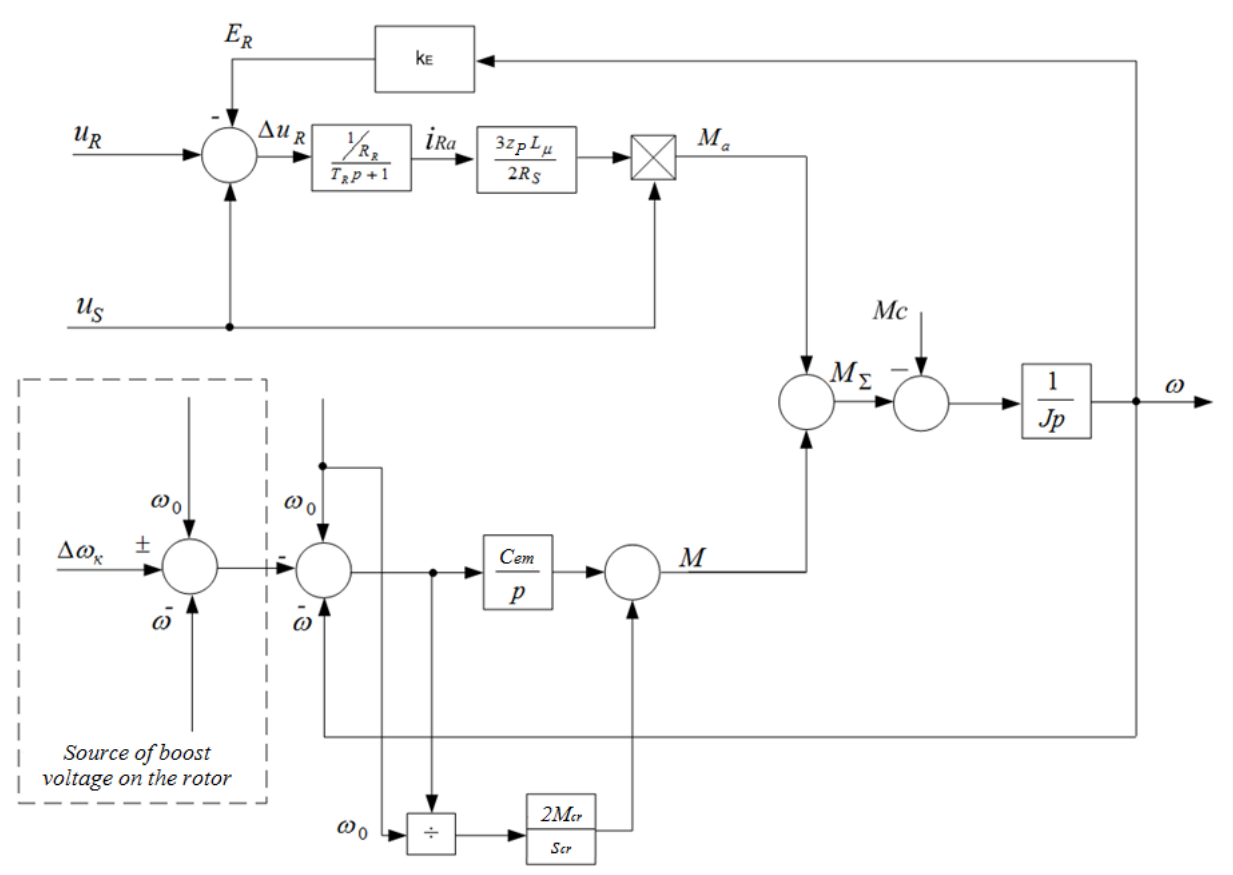

Fig. 1. Equivalent structure of a doubly-fed induction motor with a change in boost voltage frequency. 
In the equations of system (1) and the diagram shown in Fig. 1, the following designations are adopted: $k_{T}$ - transformation ratio; $R_{R}, R$ - respectively, own and additional active resistance of the rotor; $T_{R}$ - electromagnetic constant of rotor time; $T_{f}$ - constant of filter time; $I_{R}, i_{R i}$ - active component of the rotor current; $z_{P}$ - number of pole pairs; $L_{\mu}-$ the mutual inductance of the stator and rotor windings; $R_{S}$ - active resistance of the stator; $U_{S}-$ stator voltage; $\omega_{0}$ - rotation speed of the stator magnetic field; $\omega$ - angular speed of rotor rotation; $C_{e m}$ - electromagnetic rigidity; $M_{c r}, s_{c r}$ - critical moment and machine slip on a natural mechanical characteristic; $M_{a}, M_{\omega}$ - respectively, asynchronous and synchronous components of torque; $M$ - electromagnetic moment; $M_{c}$ - load moment.

The diagram shown in Fig. 1 allows all possible modes of DFM operation to be described. At $u_{R i}=0$ and $\Delta \omega=0$ the diagram describes a wound-rotor induction motor without a source of boost voltage on the rotor; at and the diagram describes the asynchronous mode of operation of the DFM; at $u_{R i} \neq 0$ and $\Delta \omega=0$ the circuit describes the MPE with a change in the frequency of the boost voltage. A feature of this circuit is the presence of a channel for correcting the frequency of the boost voltage, due to which the rigidity of drive mechanical characteristics can be increased.

The frequency converter in accordance with [5] is described by the system of equations:

$$
\left\{\begin{array}{l}
U_{R}=\frac{k_{C}}{T_{C} p+1} U_{r U}, \\
\Delta \omega_{k}=U_{r \omega} k_{\omega} \\
\omega_{R}=\omega+\Delta \omega_{K} \\
\Delta \omega= \pm \Delta \omega_{K}-\omega+\omega_{0} \\
u_{R}(t)=U_{R} \sin \left(\omega_{R} t\right) .
\end{array}\right.
$$

In the equations of the system (2), the following designations are adopted: $k_{C}$ - transfer coefficient of the converter; $T_{C}$ - time constant of the converter; $E_{R}-$ rotor EMF; $\Delta_{\omega k}-$ correcting frequency change; $U_{r \omega}, k_{\omega}$ - reference voltage and transmission coefficient of the converter over the frequency channel.

Based on the equations of systems (1) and (2) and the structure of the control object shown in Fig. 1, as well as the structural diagram of the machine in various modes [4-5], a block diagram of the ASCS of the electric drive of the mine hoist was drawn up. It is shown in Fig. 2. The following designations are adopted: $U_{r v}$ - voltage of setting the linear speed of the lifting vehicles; $U_{c}$ - control voltage; $T_{I G}$ - time constant of the intensity referenceinput element; $U_{r \omega}$ - voltage of setting the angular speed of rotor rotation $U_{\text {rilim }}$ - voltage for setting the limitation of the active component of the rotor current; $u_{\omega}$-voltage feedback on the angular speed of rotor rotation; ; $W_{S R}$ - transfer function of the angular speed regulator $U_{r T}$ - voltage reference of electromagnetic torque; $u_{i}$ - feedback voltage for the active component of the rotor current; $W_{C R}$ - transfer function of the rotor current regulator; $U_{r U}$ - reference voltage of boost voltage; $U_{r i}$ - voltage reference of the rotor current; $k_{o}, T_{o}$ - transmission coefficient and time constant of a controlled current converter (CCC) [8].

\section{Study of the obtained model}

The simulation results of the drive operation in accordance with the proposed model are shown in Fig. 3 and 4. The simulation showed the feasibility of the drive operation algorithm proposed in [1] and the possibility of controlling the DFM as a function of speed with switching asynchronous and synchronous modes of operation. 


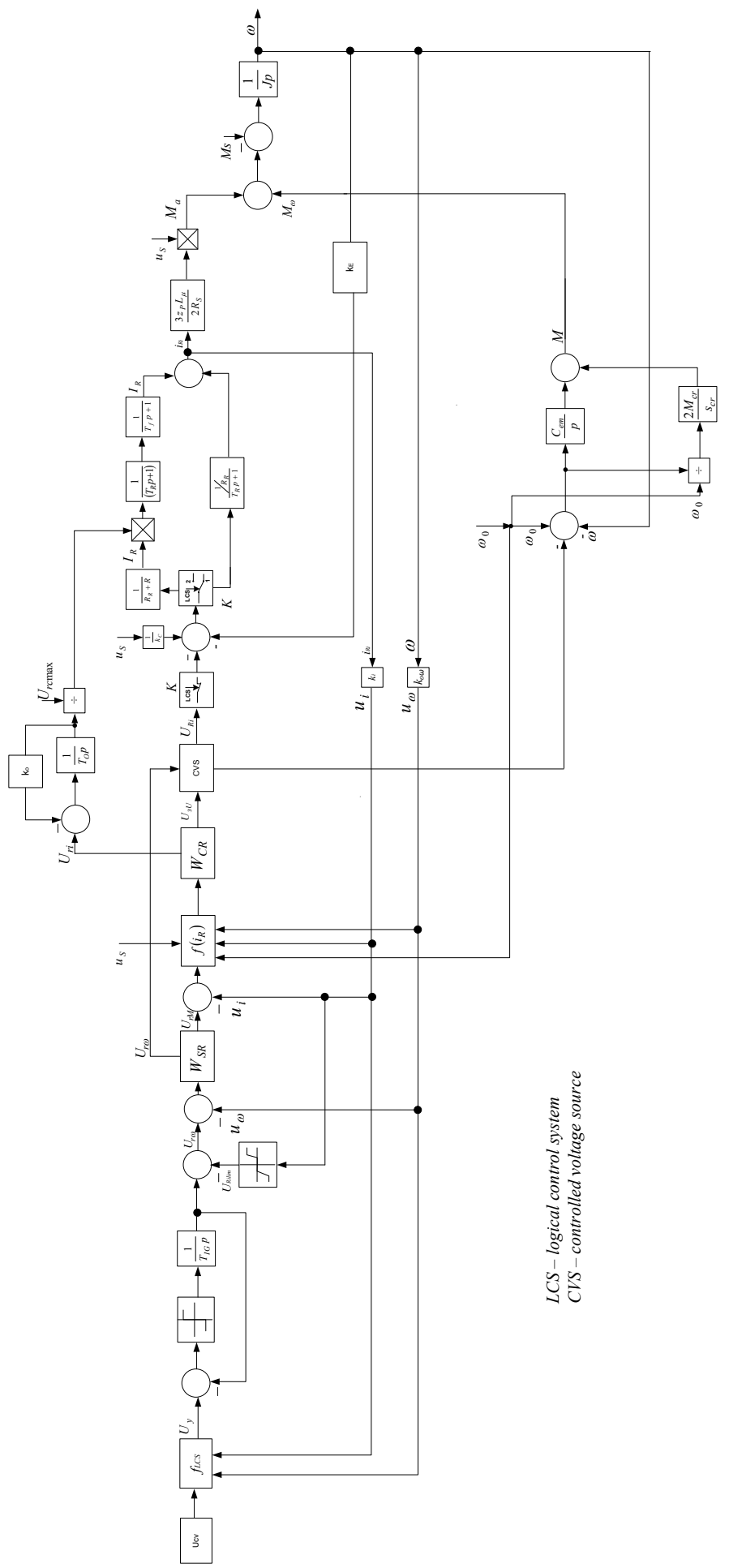

Fig. 2 Block diagram of ASCS model for mine hoist electric drive with DFM. 
The graphs in Fig. 3 and 4 show that deep regulation of the machine speed is carried out while maintaining the overload capacity of the machine and ensuring the required dynamic drive torque according to technological conditions [9-12].

Thus, the DFM control algorithm proposed in [1] ensures the regulation of the machine speed in the required range while maintaining the overload capacity of the machine. At the same time, the switching of the ASCS structure, corresponding to the transitions between the modes of operation of the machine, do not cause fluctuations in the speed and torque of the machine. Thus, the efficiency of the proposed control algorithm was proved.

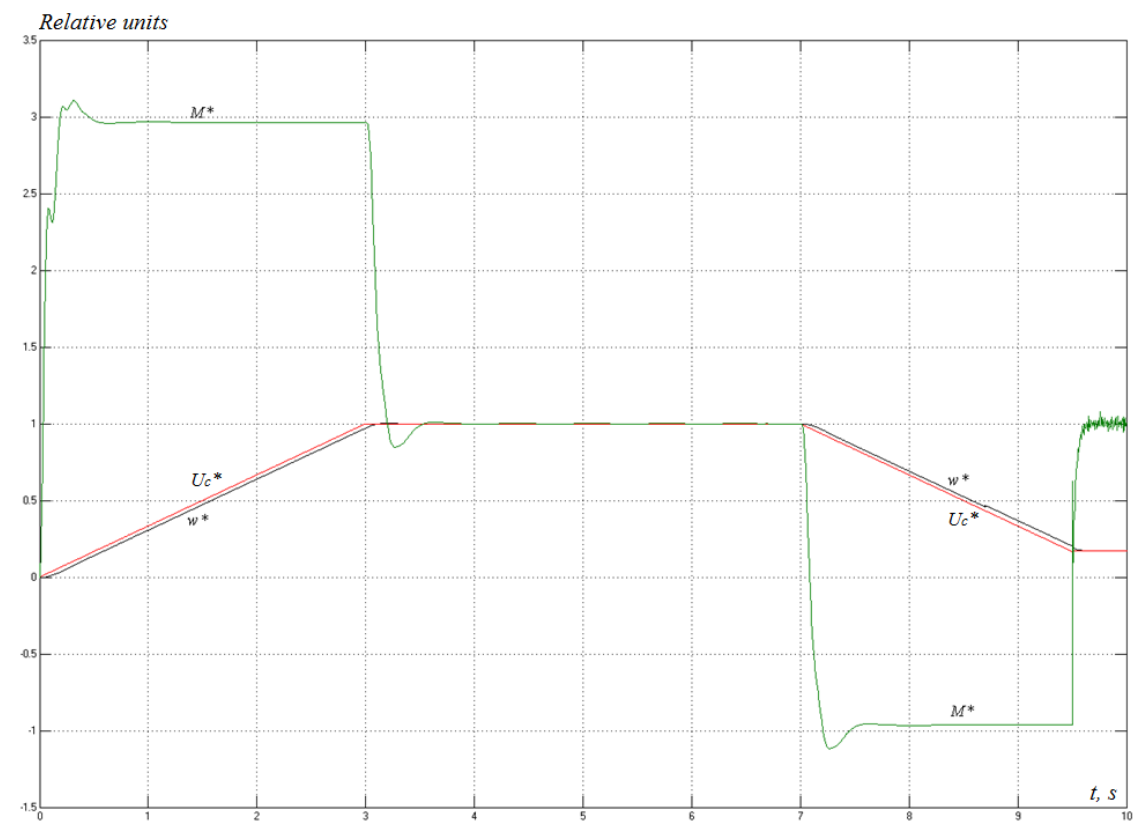

Fig. 3 Modeling results of electric drive operation based on DFM for a hoist with a three-period speed diagram.

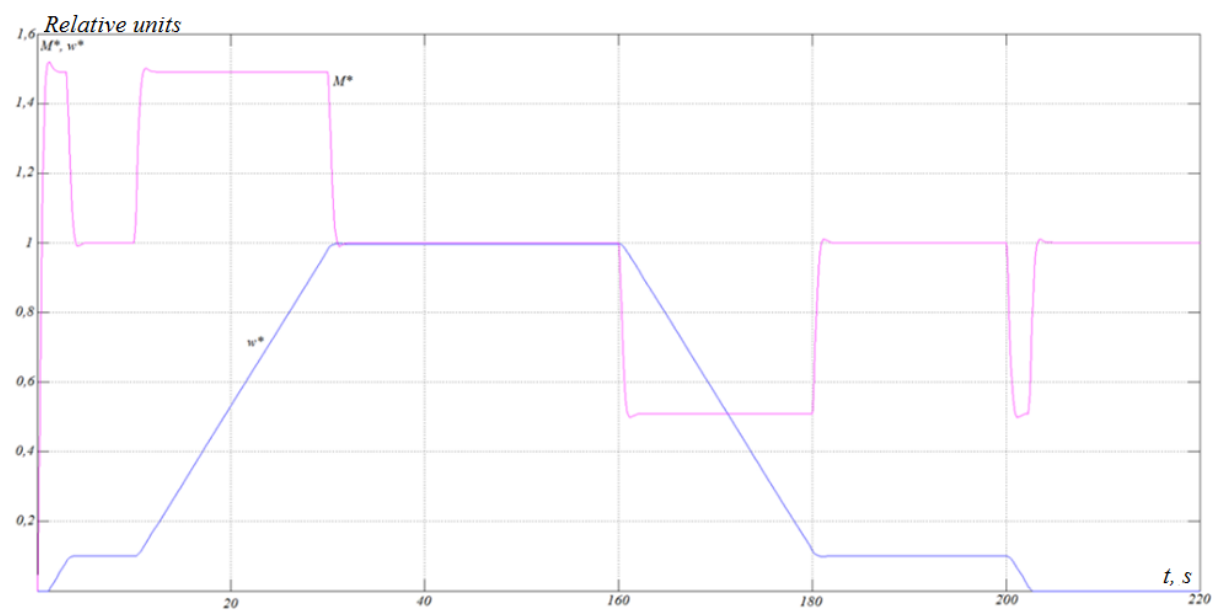

Fig. 4 Modeling results of electric drive operation based on DFM for a hoist with a seven-period speed diagram. 


\section{Conclusion}

In view of the foregoing considerations the following conclusions can be drawn:

1. The model structure of a wound-rotor induction motor, suitable for use in electric drive control systems, was proposed.

2 . The proposed model of a wound-rotor induction motor makes it possible to examine and observe not only the basic electromechanical characteristics and quality of control processes, but also to evaluate the influence of the frequency deviation of the additional power source in the rotor circuit. This allows the corrective actions in frequency to be implemented.

3. It is possible to create a control system for an electric drive with the required rigidity of mechanical characteristics at a speed control range of 40:1 required for a hoist.

4. The proposed structure of the control system can be used not only in the design and study of control processes, but also when setting up and operating an electric drive. For digital control systems, the proposed mathematical model completely coincides with the physical one and is implemented in a specific technical structure.

\section{References}

1. V.Yu. Ostrovlyanchik, I.Yu. Popolzin, IOP Conf. Series: EES, 377 (2019)

2. B. Hopfensperger, D. Atkinson, R. Lakin, Int. Trans. on Elect. Energy Sys., 12-6, $427-$ 37 (2002)

3. B.I. Firago, L.B. Pavlyachik, Adjustable AC drives (Tekhnoperspektiva, Minsk, 2006)

4. S.G. German-Galkin, Bull. of Ural St. Univ. of Railways, 3(15), 24-34 (2012)

5. V.Yu. Ostrovlyanchik, I.Yu. Popolzin, IOP Conf. Series: EES, 377 (2019)

6. V.Yu. Ostrovlyanchik, I.Yu. Popolzin, IOP Conf. Series: MSE, 354 (2018)

7. G.B. Onishchenko, I.L. Lokteva Asynchronous valve cascades and dual power motors (Energiya, Moscow, 1979)

8. V.Yu. Ostrovlyanchik, I.Yu. Popolzin, et al., Mining Equipment and Electromechanics, 1, 40-46 (2019)

9. V.R. Bezhok, et al., Mine hoist (Donetsk, Yugo-Vostok LTD, 2007)

10. V.R. Bezhok, et al., Manual on the revision and adjustment of a mine hoist (Donetskchina, Donetsk, 2009)

11. L.Kh. Datskovskii, et al., Russian Electrical Engineering, 81-1, 15-30 (2010)

12. A.V. Pesvianidze, Calculation of mine hoists (Nedra, Moscow, 1992) 